\title{
Entrainment of a thalamocortical neuron to periodic sensorimotor signals
}

\author{
Dennis Guang Yang ${ }^{*}$, Yixin Guo \\ From Twentieth Annual Computational Neuroscience Meeting: CNS*2011 \\ Stockholm, Sweden. 23-28 July 2011
}

In this work we study the dynamics of a 3-dimensional conductance-based model of a single thalamocortical (TC) neuron in response to sensorimotor signals. In particular, we focus on the entrainment of the system to a periodic excitatory signal that alternates between 'on' and 'off' states lasting for time $T_{1}$ and $T_{2}$, respectively. By exploiting invariant sets of the system and their associated invariant fiber bundles that foliate the phase space, we reduce the dynamics to the composition of two 2-dimensional maps, with the two components of one of the maps being simply a uniform shift and a uniform decay. With this reduction in computational complexity, we are able to analyze the model's response to the excitatory signal while varying $T_{1}$ and $T_{2}$ systematically. We find that for fixed $T_{2}$ but different $T_{1}$ there exist and in some cases co-exist entrained periodic oscillations with different number of spikes (see Figure 1 for the case with $\mathrm{T}_{2}=60$ milliseconds). For relatively large $\mathrm{T}_{2}$ (above 55 milliseconds) it is also possible that the model responds to the excitatory signal with delayed

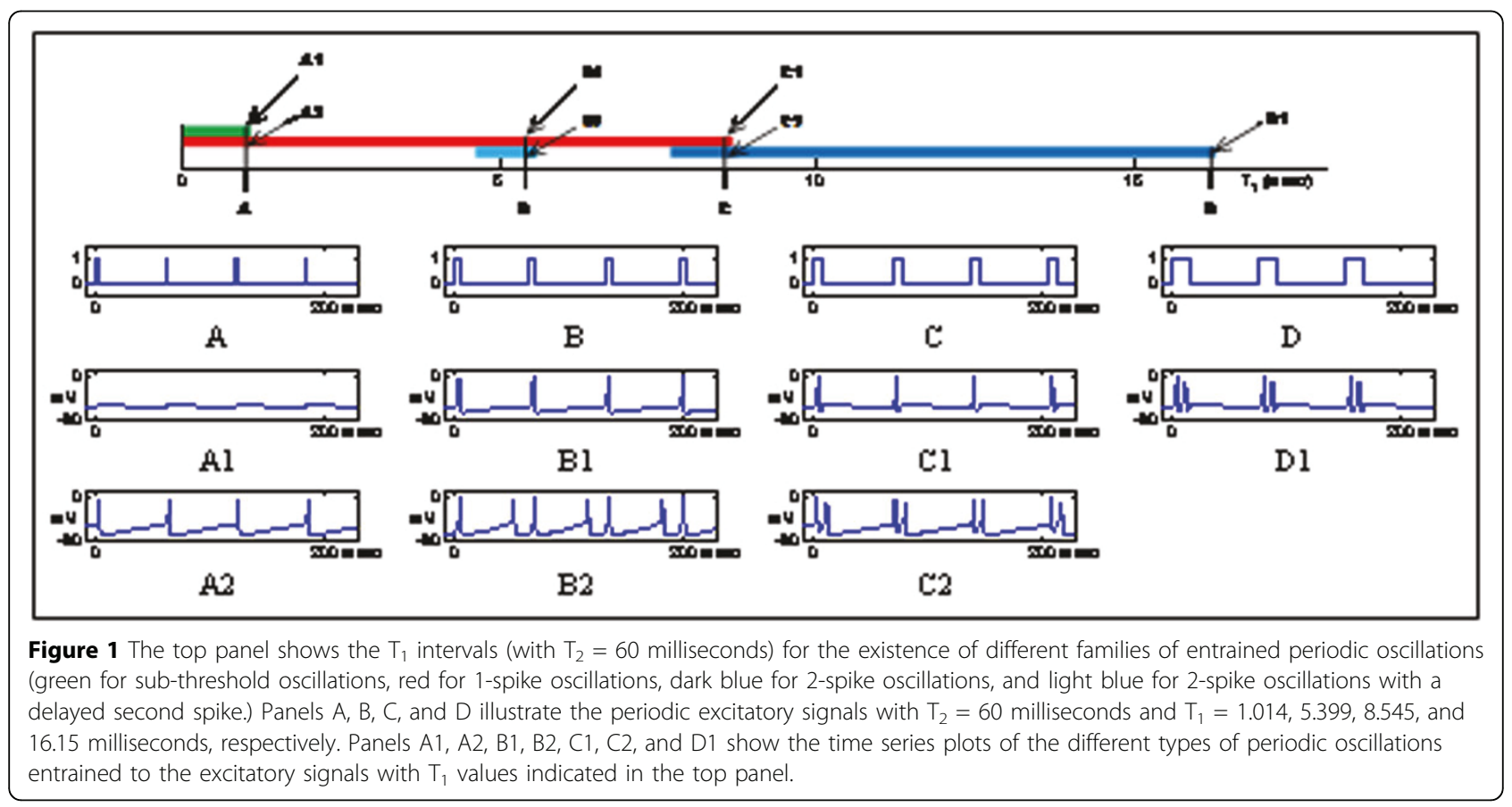

\footnotetext{
* Correspondence: yixin@math.drexel.edu

Departmentof Mathematics, Drexel University, Philadelphia, PA 19104, USA

Full list of author information is available at the end of the article
}

\section{Ciomed Central}

(c) 2011 Yang and Guo; licensee BioMed Central Ltd. This is an open access article distributed under the terms of the Creative Commons Attribution License (http://creativecommons.org/licenses/by/2.0), which permits unrestricted use, distribution, and reproduction in any medium, provided the original work is properly cited. 
spikes. Furthermore, we find that the size of the $\mathrm{T}_{1}$ intervals that allow coexistence of different types of entrained oscillations becomes larger as $\mathrm{T}_{2}$ increases.

Published: 18 July 2011

\section{Reference}

1. Guo Y, Rubin JE, McIntyre CC, Vitek JL, Terman D: Thalamocortical relay fidelity varies across subthalamic nucleus deep brain stimulation protocols in a data-driven computational model. J Neurophysiol 2008, 99:1477-1492.

doi:10.1186/1471-2202-12-S1-P135

Cite this article as: Yang and Guo: Entrainment of a thalamocortical neuron to periodic sensorimotor signals. BMC Neuroscience 201112 (Suppl 1):P135.

Submit your next manuscript to BioMed Central and take full advantage of:

- Convenient online submission

- Thorough peer review

- No space constraints or color figure charges

- Immediate publication on acceptance

- Inclusion in PubMed, CAS, Scopus and Google Scholar

- Research which is freely available for redistribution

Submit your manuscript at www.biomedcentral.com/submit 